\title{
Mindfulness meditation for workplace wellness: An evidence map
}

\author{
Lara G. Hilton ${ }^{\mathrm{a}, \mathrm{b}}$, Nell J. Marshall ${ }^{\mathrm{c}, \mathrm{d}}$, Aneesa Motala ${ }^{\mathrm{a}}$, Stephanie L. Taylor ${ }^{\mathrm{e}, \mathrm{f}}$, Isomi M. Miake-Lye ${ }^{\mathrm{c}}$, \\ Sangita Baxi ${ }^{\mathrm{a}}$, Roberta M. Shanman ${ }^{\mathrm{a}}$, Michele R. Solloway ${ }^{\mathrm{g}}$, Jessica M. Beroes ${ }^{\mathrm{c}}$ \\ and Susanne Hempel ${ }^{\mathrm{a}, *}$ \\ ${ }^{a}$ Evidence-Based Practice Center (EPC), RAND Corporation, Santa Monica, CA, USA \\ ${ }^{\mathrm{b}}$ Deloitte Consulting LLP, Los Angeles, CA, USA \\ ${ }^{\mathrm{c}}$ Evidence-Based Synthesis Program (ESP) Center,West Los Angeles VA Medical Center, Los Angeles, CA, USA \\ ${ }^{\mathrm{d}}$ VA Palo Alto Healthcare System, Palo Alto, CA, USA \\ ${ }^{\mathrm{e}}$ VA Greater Los Angeles Healthcare System, Los Angeles, CA, USA \\ ${ }^{\mathrm{f}}$ Department of Health Policy, UCLA, Los Angeles, CA, USA \\ ${ }^{\mathrm{g}}$ Child and Adolescent Health Measurement Initiative, Department of Population, Family and Reproductive \\ Health, Johns Hopkins School of Public Health, Baltimore, MD, USA
}

\begin{abstract}
.
BACKGROUND: Mindfulness interventions aim to foster greater attention and awareness of present moment experiences. Uptake of mindfulness programs in the workplace has grown as organizations look to support employee health, wellbeing, and performance.

OBJECTIVE: In support of evidence-based decision making in workplace contexts, we created an evidence map summarizing physical and mental health, cognitive, affective, and interpersonal outcomes from systematic reviews of randomized controlled trials (RCTs) of mindfulness interventions.

METHODS: We searched nine electronic databases to July 2017, dually-screened all reviews, and consulted topic experts to identify systematic reviews on mindfulness interventions. The distribution of evidence is presented as an evidence map in a bubble plot.

RESULTS: In total, 175 systematic reviews met inclusion criteria. Reviews included a variety of mindfulness-based interventions. The largest review included 109 randomized controlled trials. The majority of these addressed general health, psychological conditions, chronic illness, pain, and substance use. Twenty-six systematic reviews assessed studies conducted in workplace settings and with healthcare professionals, educators, and caregivers. The evidence map shows the prevalence of research by the primary area of focus. An outline of promising applications of mindfulness interventions is included.

CONCLUSIONS: The evidence map provides an overview of existing mindfulness research. It shows the body of available evidence to inform policy and organizational decision-making supporting employee wellbeing in work contexts.
\end{abstract}

Keywords: Systematic review, organizational behavior, complementary and integrative health

\section{Introduction}

*Address for correspondence: Susanne Hempel, RAND Corporation, 1776 Main Street, PO Box 2138, Santa Monica, CA 904072138, USA. Tel.: +1 310393 0411; E-mail: susanne_hempel @ rand.org.
Increased use of the complementary integrative health practice called "mindfulness meditation" is evident in occupational health. Based on ancient Eastern meditation practices, mindfulness is a 
non-religious practice that facilitates an attentional stance of detached observation. It is characterized by paying attention to the present moment with openness, curiosity, and acceptance $[1,2]$. Psychologists and medical providers have turned to mindfulness for therapeutic use and created manualized protocols to treat a myriad of clinical conditions such as stress and chronic pain. Non-clinical populations are using these protocols to support wellness. The most commonly used ones are described in Table 1 [1].

Organizations are adopting approaches such as mindfulness to improve workplace functioning and support optimal performance of employees [3]. Prominent companies such as Google, Aetna, and General Mills are offering employees mindfulness training to improve their effectiveness [4] and thirteen percent of U.S. workers report engaging in mindfulness-enhancing practices [5]. Empirical research on the effectiveness of mindfulness in the workplace has accelerated [6-8]. Emerging literature in organizational psychology and management suggests that mindfulness is linked to better workplace functioning [9] and recent findings from research on human service professionals suggest that cultivating resilience and mindfulness may assist in preventing psychological distress burnout and secondary traumatic stress [10]. By far the largest base of evidence is found in disciplines such as biomedicine and health, evaluating physical, mental, cognitive, affective, and interpersonal outcomes.

\subsection{Objective}

The aim of this evidence mapping study is to present an overview of mindfulness intervention research and summarize the vast body of findings on health and wellness for evidence-based decisionmaking in workplace contexts.

\section{Methods}

Evidence maps are umbrella reviews that are based on a systematic search of a broad research field [11]. Systematic reviews search multiple sources, screen studies against inclusion and exclusion criteria, and summarize results across studies, often aggregating data in meta-analyses. To give a broad indication of the effectiveness of mindfulness interventions, we used the results reported across randomized controlled trials (RCTs) as they provide the most rigorous research design for intervention assessment.

\subsection{Data sources and searches}

We searched AMED (Allied and Complementary Medicine database), Campbell Collaboration database, CDSR (Cochrane Database of Systematic Reviews), CINAHL, DARE (Database of Abstracts of Reviews of Effects), PsycINFO, PubMed, Scopus, and the Web of Science to identify English-language

Table 1

Interventions based on Mindfulness Meditation

\begin{tabular}{|c|c|}
\hline Name & Description \\
\hline $\begin{array}{l}\text { Mindfulness-Based Stress Reduction } \\
\text { (MBSR) }\end{array}$ & $\begin{array}{l}\text { In addition to mindfulness meditation, MBSR involves teaching of body scan or } \\
\text { yoga to encourage open non-judgmental observation and acceptance of painful } \\
\text { or unpleasant sensation, negative thoughts, or emotions instead of cognitively } \\
\text { appraising them, and increasing anticipatory anxiety, avoidance, or other } \\
\text { maladaptive patterns. }\end{array}$ \\
\hline $\begin{array}{l}\text { Mindfulness-Based Cognitive Therapy } \\
\text { (MBCT) }\end{array}$ & $\begin{array}{l}\text { In addition to mindfulness meditation, MBCT encourages acceptant } \\
\text { non-judgmental observation of negative thoughts and emotions instead of their } \\
\text { cognitive appraisal triggering ruminative negative thoughts, and habitual } \\
\text { emotional reactivity. }\end{array}$ \\
\hline $\begin{array}{l}\text { Mindfulness-Based Relapse Prevention } \\
\text { (MBRP) }\end{array}$ & $\begin{array}{l}\text { In addition to mindfulness meditation, MBRP teaches relapse prevention skills, } \\
\text { and non-judgmental, open and acceptant observation of cravings. It aims to } \\
\text { decouple the negative thoughts and emotions that are associated with cravings, } \\
\text { and relapse. }\end{array}$ \\
\hline Mindfulness Training for Smoking (MTS) & $\begin{array}{l}\text { In addition to mindfulness meditation, MTS provides targeted training in how to } \\
\text { apply mindfulness to specific determinants of a particular condition, for example } \\
\text { used for smoking cessation. }\end{array}$ \\
\hline $\begin{array}{l}\text { Mindfulness-Oriented Recovery } \\
\text { Enhancement (MORE) }\end{array}$ & $\begin{array}{l}\text { In addition to mindfulness meditation, MORE teaches neutral, open, and acceptant } \\
\text { observation of painful sensations. It also incorporates positive psychology, and } \\
\text { behavioral techniques directed towards neuroscientific underpinnings of } \\
\text { addiction. }\end{array}$ \\
\hline
\end{tabular}


systematic reviews focusing on mindfulness interventions from database inception to July 2017. Additionally, we screened published reviews of reviews and consulted with topic experts. This research builds on a larger project to inform evidencebased decision making at the US Department of Veterans Affairs [12]. The project was supported by an expert panel.

\subsection{Study selection}

To be included in the evidence map, publications had to meet the following four criteria. First, they had to be systematic reviews of mindfulness interventions summarizing primary research. We included publications that self-identified as a "systematic review," documented the search sources, and accounted for identified studies. Reviews including community dwelling participants using mindfulness for any health-related indication were eligible. Reviews of adults or unspecified age groups were included; reviews exclusively focusing on children, adolescents, or elderly participants were excluded. In addition, broad reviews not specific to mindfulness were eligible if the term "mindfulness" was part of the search strategy and reviews with search strategies that did not specify any intervention (e.g., focused on a patient population) and that identified mindfulness studies were also included. Reviews that included mindfulness studies but did not systematically search for these (e.g., by reviewing "meditation" interventions where only those mindfulness studies were found that used the descriptive term "meditation") were excluded. Third, health and wellbeing measures, including physical, mental, cognitive, and affective outcomes were eligible. We included clinical conditions or wellness outcomes that affect working adults (e.g., diabetes or depression) but we excluded psychosis or intellectual disability-focused reviews. Frequency of use, cost, study design features, intervention features, or physiological or mechanistic outcomes (e.g., neurobiological changes) were also excluded. We included English-language reviews regardless of language of included studies and publication date.

Two literature reviewers independently screened the search results. Citations deemed potentially relevant by at least one reviewer were obtained as full text. Full text publications were screened against the inclusion criteria by both independent reviewers; disagreements were resolved through discussion. We documented reasons for exclusion and recorded the literature flow in an electronic database.

\subsection{Data abstraction and critical appraisal}

A content expert and experienced systematic reviewer extracted the review topic, number of included mindfulness RCTs, the comparator, and the results using a pilot tested data extraction form. We documented the format type of mindfulness intervention used, differentiating structured programs such as Mindfulness Based Stress Reduction (MBSR) or Mindfulness Based Cognitive Therapy (MBCT), and other mindfulness-based intervention approaches. We abstracted the author-reported results using the documented metrics such as standardized mean differences (SMD) together with the 95\% confidence interval (CI). To address the validity of the systematic review, we extracted whether the review was published by an organization known for their expertise and high quality systematic reviews (e.g., Cochrane reviews).

\subsection{Data synthesis and analysis}

The evidence base was distilled into a broad visual overview using the format of a bubble plot. We used five dimensions to display information: the X-axis; $y$-axis; and the number, size, and color of the bubbles.

Topic (number of bubbles): We used the topics reported by the review authors to categorize the reviews. Reviews focused on outcomes or clinical indications. All identified systematic reviews were allocated to a single content area and did not enter the bubble plot multiple times. Literature size (yaxis): We used the number of included RCTs in the largest review on a topic area as the research volume estimate. The plot includes systematic reviews that have explicitly searched for RCTs but did not find any on the topic. Reviews vary in their inclusion criteria but a well-established research design, such as an RCT, is likely to be included in all reviews and provides a broad estimate of the research volume. Effect (x-axis): The evidence map provides a very broad indication of the effectiveness of mindfulness interventions per the outcomes reported in RCTs (differentiating evidence of potentially no effect, unclear evidence, and evidence of a potential positive effect). Most emphasis was given to the largest review (which should provide the most complete literature synthesis), Cochrane reviews (given their methodological rigor), or reports from agencies specializing 
in unbiased systematic reviews such as Agency for Healthcare Research and Quality (AHRQ) reports. Systematic reviews (bubble size): We used the size of the bubble to document the number of reviews on the topic. Workplace setting (color): We highlighted evidence exclusively addressing workplace interventions and employee wellness (i.e., social workers, healthcare providers).

The evidence base was summarized in a narrative synthesis. All included systematic reviews are included in the reference section to provide more information for the interested reader.

\section{Results}

The search identified 1,024 citations. Title and abstract screening yielded 320 publications which we obtained as full text. We identified 175 unique systematic reviews meeting the inclusion criteria [13-187].

The distribution of evidence is shown in Fig. 1. The $y$-axis shows that many research studies have evaluated mindfulness interventions. The largest review, that included research studies evaluating mindfulness interventions and that reported on health outcomes (health-all), included 109 RCTs [21].

The large number of bubbles demonstrates that mindfulness approaches have been applied in a variety of individual applications, addressing different participant groups, clinical indications, or health outcomes. The evidence map differentiated 39 topic areas to document the available research. The number of systematic reviews per topic area ranged from a single review to 18 identified systematic reviews published on the topic.

The evidence map aims to give a broad indication of the effectiveness of the interventions. The map documents that a large proportion of the existing evidence base is unclear with respect to the effectiveness of the interventions. Reviews either included only a single study without replication of results, reported conflicting results across studies or did not provide summary estimates across studies, while reviews sometimes came to different conclusions.

\subsection{Mindfulness interventions in work contexts}

We identified 28 reviews that addressed the health and wellness of healthcare professionals, social workers, informal caregivers, educators, or general work populations.
Twelve systematic reviews focused on outcomes for healthcare professionals [64, 76, 83, 109, 110, $113,114,121,132,155,159,177]$. The largest review included 17 RCTs [155], reported positive results, and suggested that MBSR and mindfulness meditation are effective in reducing nurses' state anxiety (SMD -0.78; CI -1.39 to -0.18; 6 RCTs) and depression (SMD -0.51 ; CI -0.78 to $-0.18,4$ RCTs) but not trait anxiety (SMD $-0.67 ;-1.52,0.18 ; 3 \mathrm{RCTs}$ ) or stress (SMD -0.34; CI -2.67, 1.99; 5 RCTs) [155]. A second review reported reduced stress (SMD -0.54 ; CI $-0.85,-0.24 ; 3$ RCTs) but no statistically significant effect for anxiety, depression, or burnout [109]. A review on compassion fatigue identified only one relevant RCT [177] and a review on stress management in medical education did not identify any relevant RCTs [64]. The remaining reviews did not provide intervention effect estimates, reported no summary for mindfulness interventions, or did not report effects for RCTs specifically [76, 83, 110, 113, $114,121,132,159]$.

We identified seven reviews of mindfulness interventions for informal or family caregivers [101, $108,118,135,136,161,176]$; three of these focused exclusively on MBSR and MBCT [101, 108, 136]. A meta-analysis showed positive effects postintervention for stress (Hedges g 0.57; CI 0.23, 0.92; 3 RCTs) and depression (Hedges' g -0.62; CI -0.97, -0.27 ; 3 RCTs) [136]. The other reviews did not present summary effects [116, 132, 156, 169].

Three reviews were found on educators and they summarized a mix of MBSR and other mindfulness interventions. The largest review with 12 RCTs found unclear results of an effect of mindfulness on anxiety, depression, stress and burnout [112]. A second review showed unclear evidence for teacher functioning [171] and the third described positive results for teacher well-being and performance but did not provide a summary estimate [167].

Four reviews addressed general workplace populations $[145,164,168,170]$. The largest included nine RCTs evaluating interventions on office staff, healthcare professionals, and teachers and found positive effects on distress but did not report effect estimates for RCT data [145]. Another review focused on job burnout and reported that the majority of the studies showed positive results but did not report an effect estimate [168]. A third review included people who work in manufacturing, healthcare, offices, and schools found mixed results for stress, burnout, and general mental health [170]. A fourth evaluated brief mental health and well-being interventions in 


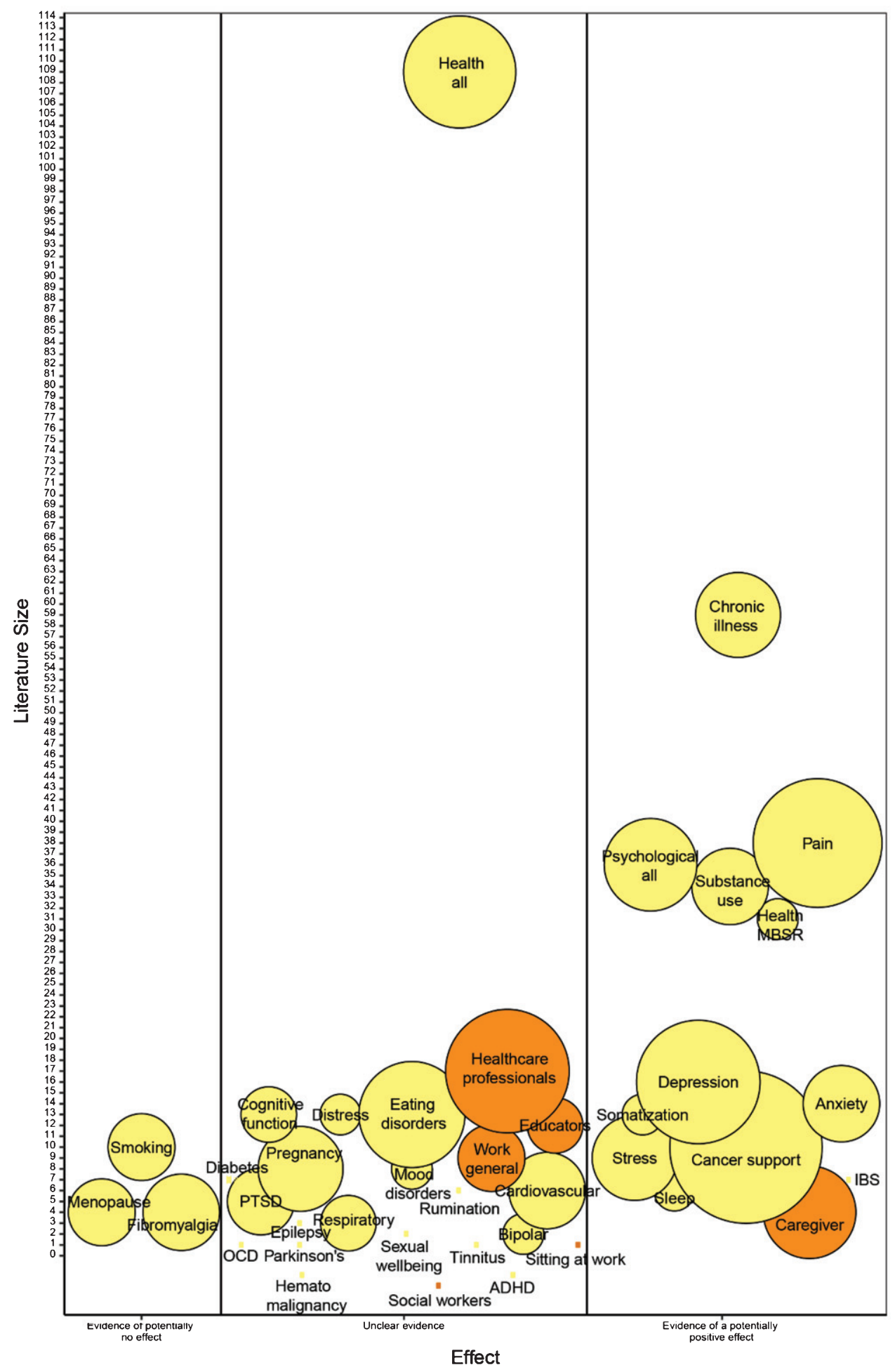

Fig. 1. Mindfulness Meditation for Workplace Wellness. 
organizational settings; the review did not stratify effects by intervention but identified one mindfulness meditation study [164].

We identified a Cochrane review dedicated to identifying workplace interventions for reducing sitting at work [175]. The review reported that mindfulness training did not reduce workplace sitting time but the result was based on only one study. One review focused exclusively on social workers but did not identify any relevant RCTs [146].

\subsection{Most promising areas in health and wellness}

Six systematic reviews addressed mindfulness interventions in chronic illness [42, 46, 117, 151, 182, 188]. The largest included 59 RCTs and did not present summary estimates but concluded there is partial evidence for mindfulness-based interventions to provide short-term benefits across a wide range of lifestyle medicine-relevant populations and study outcomes [182]. A review of chronic somatic diseases reported positive effects for psychological distress (SMD 0.32; CI 0.13, 0.50; 3 RCTs), depression (SMD 0.26; CI 0.18, 0.34; 6 RCTs), and anxiety (SMD 0.47; CI 011, 0.83; 4 RCTs) comparing MBSR to waitlist and support groups [46]. The remaining reviews did not provide summary effect estimates for mindfulness-based interventions. Many reviews addressed pain $[28,30,40,81,88,130,149$, $152,156,165,179,184,186]$. The largest review included 38 RCTs on various mindfulness interventions including MBCT, MBSR, and others [130] and found low-quality evidence that mindfulness meditation is associated with a small decrease in pain compared with treatment as usual, passive controls, or education/support groups (SMD, 0.32; 95\% CI, $0.09,0.54 ; 30 \mathrm{RCTs}$ ) and moderate-quality evidence for quality of life from mindfulness meditation as compared with treatment as usual, support groups, education, stress management, and waitlist controls (SMD, 0.49; 95\% CI, 0.22, 0.76; 16 RCTs). Similarly, an earlier review reported positive pooled effects (MD -0.96; CI -1.64, -0.34); 4 RCTs) [152] while two other older reviews found no statistically significant effects for pain intensity, pain acceptance, or perceived pain control $[88,186]$. Our searches identified five reviews of various mindfulness interventions for substance use $[25,50,73,134,173]$. The largest review included 34 RCTs [134]. Interventions evaluated in the review included Mindfulness-Based Relapse Prevention (MBRP), Mindfulness-Oriented Recovery Enhancement (MORE), and mindfulness treatment. The effects of mindfulness interventions compared to psychotherapeutic treatment and inactive controls were positive for substance use measures (Cohen's d -0.33; CI -0.49, -0.17; 6 RCTs) and craving (Cohen's d -0.68; CI -1.11, -0.25; 9 RCTs).

We identified seven systematic reviews that addressed psychological wellbeing (psychologicalall) $[13,75,77,80,84,95,96]$. The largest review included 36 RCTs and was based on an AHRQ report on meditation programs for psychological stress and wellbeing, which classified MBSR, MBCT, Vipassana, Zen, and other mindfulness meditation as mindfulness-based [13, 189]. The review reported positive effects for anxiety (Cohen's d 0.38; CI 0.12, 0.64 ; at 8 weeks; 0.22 ; CI $0.02,0.43$; at $3-6$ months; 8 RCTs total), depression (0.30; CI $-0.00,0.59$; at 8 weeks; 0.23 ; CI $0.05,0.42$ at 3-6 months; 10 RCTs total); and pain ( 0.33 ; CI, 0.03 to $0.62 ; 4$ RCTs) compared to control interventions matched in time and attention [13]. The AHRQ report also showed a positive effect on negative affect (general anxiety, stress/distress, and depression outcomes combined; SMD -0.34; CI -0.53, -0.14 ; 10 RCTs). Data on stress/distress varied by comparator, and the pooled results for the mental health related quality of life, positive affect, and sleep were negative, and there was insufficient evidence for positive mood. Another large review with 17 RCTs reported an effect size of Cohen's d 0.396 (CI 0.19, 0.61; 17 RCTs) across all psychological outcomes compared, primarily, to waitlist [77]. The review considered 48 different psychological variables and reported positive pooled effects for stress (SMD 0.792; CI 0.371, 1.123; 4 RCTs), distress (SMD 0.547; CI 0.193, 0.901; 6 RCTs), depression (SMD 0.512; CI 0.164, $0.861 ; 5$ RCTs), and anxiety (SMD 0.435; CI 0.141, $0.729 ; 3$ RCTs). It concluded that MBSR compared to waitlist is effective across a broad range of psychological outcomes but comparisons with other forms of treatment are less favorable. The Campbell Collaboration review on MBSR also reported positive results for individual as well as combined mental health outcomes (SMD 0.53; CI 0.46, 0.61; 26 RCTs), measures of personal development (SMD 0.50; CI 0.35, $0.66 ; 12$ RCTs), and quality of life (SMD 0.57; CI $0.17,0.96 ; 4$ RCTs) [79]. The review also addressed other health benefits (health-MBSR) and included 31 RCTs [79]. The review included training programs based on the protocol elements specified by Kabat-Zinn (body-scan exercises, mental exercises focusing attention on breathing, physical exercises focusing on the awareness of bodily sensations, and 
the practice of being fully aware during everyday activities). It reported positive effects for the combined outcome mental health (SMD 0.53; CI -0.43, $0.64 ; 26$ RCTs) and somatic health (SMD 0.31; CI $0.10,0.52 ; 10 \mathrm{RCTs}$ ) compared to waitlist and usual care. The review concluded that MBSR has a moderate and consistent effect on many measures of mental health for a wide range of target groups and appears to improve elements of personal development such as empathy and coping, enhances mindfulness and quality of life, and improves some aspects of somatic health. The review also noted that there is a lack of data on social function, work ability, and long-term effects.

We identified 12 systematic reviews focusing on depression $[32,35,37,51,56,66,70,74,85,87$, 106, 119] and the largest included 16 RCTs [119]. Their meta-analysis estimated the effect of MBCT in a group format compared to waitlist or no treatment, and this pooled analyses produced large effects for depression (SMD -0.76; CI $-0.95,-0.56$; 16 RCTs) [119]. The Campbell Collaboration review on MBSR supported the positive findings (SMD 0.54; CI 0.35, 0.74; 9 RCTs) [79]. Further, an AHRQ report on mindfulness meditation programs reported positive effects for depression (SMD 0.30; CI 0.00, 0.59; at 8 weeks; 0.23 ; CI $0.05,0.42$ at $3-6$ months; 10 RCTs) [13]. We identified 18 systematic reviews that addressed the role of mindfulness interventions in cancer care (cancer support) $[18,20,29,31,34$, $36,39,45,55,58,60,62,94,103,120,143,147$, 169, 190]. The largest review included ten RCTs and reported that compared to usual care, significant post-intervention effects of MBSR or MBCT were found for health-related quality of life (SMD 0.21; CI 0.04,.39), fatigue (SMD -0.28; CI -0.43 , -0.14 ), sleep (SMD -0.23 ; CI $-0.40,-0.05$ ), stress (SMD -0.33; CI -0.61, -0.05), anxiety (SMD -.28; CI $-0.39,-0.16$ ), and depression (SMD -0.34; CI $-0.46,-0.21)$. Effects were maintained for six months for anxiety and depression but average effects were all below the threshold of minimal clinically important differences. Two other reviews reported positive effects for mental health outcomes (Cohen's d 0.37; CI $0.10,0.64$; 4 RCTs) and quality of life (SMD 0.32; CI $0.06,0.57 ; 2$ RCTs) $[20,55]$. The other reviews did not provide summary effects for RCT data on mindfulness interventions. We identified six systematic review addressing stress [26, 27, 52, 100, 104, 148]; the largest one focused on undergraduate students and included nine RCTs [100]. The second largest review reported a summary effect estimate, indicat- ing a medium effect for perceived stress (Hedges $\mathrm{g}$ 0.432; CI 0.202, 0.662; 8 RCTs) [104].

Positive effects were also found across studies and reviews for somatization, anxiety, irritable bowel syndrome (IBS), sleep, and, as discussed above, caregivers, but the areas have a smaller evidence base, both in terms of primary research and published reviews.

\section{Conclusion}

The evidence map provides a broad overview of the available research evidence on mindfulness interventions. These findings support and extend the current efforts underway to apply mindfulness interventions in work contexts to enhance employee health, wellness, and performance $[3,9,191]$. Most research is related to general overviews of health benefits. Evidence of potential positive effects is documented for the topic areas chronic illness, pain, substance use, depression, anxiety, perceived stress, somatization, cancer support, and IBS. Mindfulness interventions appear to have general benefits for a range of psychological variables and research shows effects of MBSR on a variety of health outcomes and positive effects on caregivers have been documented. Mindfulness interventions have been applied to a large range of clinical indications but many areas are still based on only a small number of robust research studies.

The evidence summarizing workplace mindfulness interventions focused on groups of professionals and healthcare providers in particular. Systematic reviews of RCTs conducted in work contexts show promise for healthcare providers, nurses, and medical students but require further research for more definitive evidence statements. Positive effects are documented for caregiver burden in caregivers. These findings echo evidence from the organizational science literature [192]. Findings of effects of mindfulness interventions for educators were mixed. Additionally, barriers of feasibility and sustainability of interventions for healthcare professionals may exist, requiring further exploration [193, 194].

The evidence map has several limitations. First, the map only provides a broad overview and is not designed to provide detailed and definitive information on the effectiveness of interventions. Interested stakeholders should review the identified systematic reviews of interest to obtain a more detailed summary. Furthermore, the evidence suggests differential effects of MBSR, MBCT, and other 
mindfulness-based interventions, and definitions of "mindfulness-based" varied widely in the studies contributing to the research field. Effects of interventions are likely to vary by intervention characteristics and the comparator and the available research is based on a large spectrum of interventions. Interventions included reviews contributing to the evidence map were offered by healthcare professionals in a clinical context and it is unclear how easily the approaches will translate to work context applications (e.g., a mindfulness meditation course for employees to support wellbeing or work performance). Finally, this evidence map was designed to support wellbeing in the workplace and excluded interventions for clinical indications such as psychosis; more information on topics outside the scope of work can be found in an earlier clinically-oriented research report [12].

This evidence map provides a very broad overview of the evidence base indicating areas in which research has been conducted. The results can be used to help workplace setting stakeholders interpret the state of the evidence. The map aims to inform policy and organizational decision making in support of employee wellbeing in work contexts.

\section{Acknowledgments}

We would like to thank Paul Shekelle, Stephen Ezeji-Okoye, Laura Krejci, Jill Bormann, David Kearney, and John (Greg) Serpa for their expert advice, and Patty Smith for administrative assistance.

The manuscript is based in parts on research funded by the Department of Veterans Affairs, Veterans Health Administration, Office of Research and Development, Quality Enhancement Research Initiative. The findings and conclusions in this document are those of the authors and do not necessarily represent the views of the Department of Veterans Affairs or the United States government.

\section{Conflict of interest}

None of the authors have any conflict of interest to declare.

\section{References}

[1] UCLA Mindfulness Awareness Research Center (MARC) 2015 [May 29, 2015]. Available from: http://marc.ucla. edu/default.cfm.
[2] Kabat-Zinn J, Lipworth L, Burney R. The clinical use of mindfulness meditation for the self-regulation of chronic pain. J Behav Med. 1985;8(2):163-90.

[3] Good DJ, Lyddy CJ, Glomb TM, Bono JE, Brown KW, Duffy MK, et al. Contemplating Mindfulness at Work: An Integrative Review. Journal of Management. 2015:1-29.

[4] Forbes Human Resources Council. Can mindfulness training help businesses be effective? Forbes. 2017; https://www.forbes.com/sites/forbeshumanresourcescoun cil/2017/05/23/can-mindfulness-training-help-organizatio ns-be-more-effective\#60e98820e1ea(May 23)

[5] Olano HA, Kachan D, Tannenbaum SL, Mehta A, Annane D, Lee DJ. Engagement in mindfulness practices by U.S. adults: Sociodemographic barriers. Journal of alternative and complementary medicine (New York, NY). 2015;21(2):100-2.

[6] Spence GB. Mindfulness at Work. The Wiley Blackwell Handbook of the Psychology of Positivity and StrengthsBased Approaches at Work: wiley; 2016. pp. 110-31.

[7] Brown KW, Ryan RM, Creswell JD. Mindfulness: Theoretical Foundations and Evidence for its Salutary Effects. Psychological Inquiry. 2007;18(4):211-37.

[8] Chiesa A, Fazia T, Bernardinelli L, Morandi G. Citation patterns and trends of systematic reviews about mindfulness. Complementary Therapies in Clinical Practice. 2017;28:26-37.

[9] Glomb TM, Duffy MK, Bono JE, Yang T. Mindfulness at work. In Research. In Personnel and Human Resources Management. 2011:115-57.

[10] Harker R, Pidgeon AM, Klaassen F, King S. Exploring resilience and mindfulness as preventative factors for psychological distress burnout and secondary traumatic stress among human service professionals. Work. 2016;54(3):631-7.

[11] Miake-Lye IM, Hempel S, Shanman R, Shekelle PG. What is an evidence map? A systematic review of published evidence maps and their definitions, methods, and products. Syst Rev. 2016;5:28.

[12] Hempel S, Taylor SL, Marshall NJ, Miake-Lye IM, Beroes JM, Shanman R, et al. Evidence Map of Mindfulness. VA-ESP Project\#05-226. Washington (DC): Quality Enhancement Research Initiative (QUERI), Department of Veterans Affairs, 2014 October. Report No.

[13] Goyal M, Singh S, Sibinga EM, Gould NF, RowlandSeymour A, Sharma R, et al. Meditation Programs for Psychological Stress and Well-being: A Systematic Review and Meta-analysis. JAMA internal medicine. 2014.

[14] Lauche R, Cramer H, Dobos G, Langhorst J, Schmidt S. A systematic review and meta-analysis of mindfulness-based stress reduction for the fibromyalgia syndrome. Journal of psychosomatic research. 2013;75(6):500-10.

[15] Crawford C, Wallerstedt DB, Khorsan R, Clausen SS, Jonas WB, Walter JA. A Systematic Review of Biopsychosocial Training Programs for the Self-Management of Emotional Stress: Potential Applications for the Military. Evidence-based complementary and alternative medicine: eCAM. 2013;2013:747694.

[16] Querstret D, Cropley M. Assessing treatments used to reduce rumination and/or worry: A systematic review. Clinical psychology review. 2013;33(8):996-1009.

[17] Lakhan SE, Schofield KL. Mindfulness-based therapies in the treatment of somatization disorders: A systematic review and meta-analysis. PloS one. 2013;8(8):e71834. 
[18] Casellas-Grau A, Font A, Vives J. Positive psychology interventions in breast cancer. A systematic review. Psycho-oncology. 2014;23(1):9-19.

[19] Lawrence M, Booth J, Mercer S, Crawford E. A systematic review of the benefits of mindfulness-based interventions following transient ischemic attack and stroke. International Journal of Stroke: Official Journal of the International Stroke Society. 2013;8(6):465-74.

[20] Shneerson C, Taskila T, Gale N, Greenfield S, Chen YF. The effect of complementary and alternative medicine on the quality of life of cancer survivors: A systematic review and meta-analyses. Complementary Therapies in Medicine. 2013;21(4):417-29.

[21] Khoury B, Lecomte T, Fortin G, Masse M, Therien P, Bouchard V, et al. Mindfulness-based therapy: A comprehensive meta-analysis. Clinical Psychology Review. 2013;33(6):763-71.

[22] Lazaridou A, Philbrook P, Tzika AA. Yoga and mindfulness as therapeutic interventions for stroke rehabilitation: A systematic review. Evidence-based Complementary and Alternative Medicine : eCAM. 2013;2013:357108.

[23] Carim-Todd L, Mitchell SH, Oken BS. Mind-body practices: An alternative, drug-free treatment for smoking cessation? A systematic review of the literature. Drug and Alcohol Dependence. 2013;132(3):399-410.

[24] Kim SH, Schneider SM, Kravitz L, Mermier C, Burge MR. Mind-body practices for posttraumatic stress disorder. Journal of investigative medicine : The official publication of the American Federation for Clinical Research. 2013;61(5):827-34.

[25] Chiesa A, Serretti A. Are Mindfulness-Based Interventions Effective for Substance Use Disorders? A Systematic Review of the Evidence. Substance Use \& Misuse. 2013.

[26] Shiralkar MT, Harris TB, Eddins-Folensbee FF, Coverdale $\mathrm{JH}$. A systematic review of stress-management programs for medical students. Academic Psychiatry : The Journal of the American Association of Directors of Psychiatric Residency Training and the Association for Academic Psychiatry. 2013;37(3):158-64.

[27] Regehr C, Glancy D, Pitts A. Interventions to reduce stress in university students: A review and meta-analysis. Journal of Affective Disorders. 2013;148(1):1-11.

[28] Reiner K, Tibi L, Lipsitz JD. Do mindfulness-based interventions reduce pain intensity? A critical review of the literature. Pain Medicine (Malden, Mass). 2013;14(2):230-42.

[29] Cramer H, Lauche R, Paul A, Dobos G. Mindfulnessbased stress reduction for breast cancer-a systematic review and meta-analysis. Current Oncology (Toronto, Ont). 2012;19(5):e343-52.

[30] Cramer H, Haller H, Lauche R, Dobos G. Mindfulnessbased stress reduction for low back pain. A systematic review. BMC Complementary and Alternative Medicine. 2012;12:162.

[31] Zainal NZ, Booth S, Huppert FA. The efficacy of mindfulness-based stress reduction on mental health of breast cancer patients: A meta-analysis. PsychoOncology. 2013;22(7):1457-65.

[32] Woltz PC, Chapa DW, Friedmann E, Son H, Akintade B, Thomas SA. Effects of interventions on depression in heart failure: A systematic review. Heart \& lung : The journal of Critical Care. 2012;41(5):469-83.

[33] Vollestad J, Nielsen MB, Nielsen GH. Mindfulness- and acceptance-based interventions for anxiety disorders: A systematic review and meta-analysis. The British Journal of Clinical Psychology / the British Psychological Society. 2012;51(3):239-60.

[34] Piet J, Wurtzen H, Zachariae R. The effect of mindfulnessbased therapy on symptoms of anxiety and depression in adult cancer patients and survivors: A systematic review and meta-analysis. Journal of Consulting and Clinical Psychology. 2012;80(6):1007-20.

[35] Klainin-Yobas P, Cho MA, Creedy D. Efficacy of mindfulness-based interventions on depressive symptoms among people with mental disorders: A meta-analysis. International Journal of Nursing Studies. 2012;49(1):10921.

[36] Musial F, Bussing A, Heusser P, Choi KE, Ostermann T. Mindfulness-based stress reduction for integrative cancer care: A summary of evidence. Forschende Komplementarmedizin (2006). 2011;18(4):192-202.

[37] Piet J, Hougaard E. The effect of mindfulness-based cognitive therapy for prevention of relapse in recurrent major depressive disorder: A systematic review and metaanalysis. Clinical Psychology Review. 2011;31(6):103240.

[38] Sarris J, Camfield D, Berk M. Complementary medicine, self-help, and lifestyle interventions for obsessive compulsive disorder (OCD) and the OCD spectrum: A systematic review. Journal of Affective Disorders. 2012;138(3):21321.

[39] Matchim Y, Armer JM, Stewart BR. Mindfulness-based stress reduction among breast cancer survivors: A literature review and discussion. Oncology Nursing Forum. 2011;38(2):E61-71.

[40] Chiesa A, Serretti A. Mindfulness-based interventions for chronic pain: A systematic review of the evidence. Journal of Alternative and Complementary Medicine (New York, NY). 2011;17(1):83-93.

[41] Rakofsky JJ, Dunlop BW. Treating nonspecific anxiety and anxiety disorders in patients with bipolar disorder: A review. The Journal of Clinical Psychiatry. 2011;72(1):8190.

[42] Niazi AK, Niazi SK. Mindfulness-based stress reduction: A non-pharmacological approach for chronic illnesses. North American Journal of Medical Sciences. 2011;3(1):20-3.

[43] Chiesa A, Calati R, Serretti A. Does mindfulness training improve cognitive abilities? A systematic review of neuropsychological findings. Clinical Psychology Review. 2011;31(3):449-64.

[44] Wanden-Berghe RG, Sanz-Valero J, Wanden-Berghe C. The application of mindfulness to eating disorders treatment: A systematic review. Eating Disorders. 2011;19(1):34-48.

[45] Shennan C, Payne S, Fenlon D. What is the evidence for the use of mindfulness-based interventions in cancer care? A review. Psycho-Oncology. 2011;20(7):681-97.

[46] Bohlmeijer E, Prenger R, Taal E, Cuijpers P. The effects of mindfulness-based stress reduction therapy on mental health of adults with a chronic medical disease: A meta-analysis. Journal of psychosomatic Research. 2010;68(6):539-44.

[47] Hofmann SG, Sawyer AT, Witt AA, Oh D. The effect of mindfulness-based therapy on anxiety and depression: A meta-analytic review. Journal of Consulting and Clinical Psychology. 2010;78(2):169-83.

[48] Chiesa A. Vipassana meditation: Systematic review of current evidence. Journal of Alternative and Complementary Medicine (New York, NY). 2010;16(1):37-46. 
[49] Chiesa A, Serretti A. A systematic review of neurobiological and clinical features of mindfulness meditations. Psychological Medicine. 2010;40(8):1239-52.

[50] Zgierska A, Rabago D, Chawla N, Kushner K, Koehler R, Marlatt A. Mindfulness meditation for substance use disorders: A systematic review. Substance Abuse : Official Publication of the Association for Medical Education and Research in Substance Abuse. 2009;30(4):266-94.

[51] Parikh SV, Segal ZV, Grigoriadis S, Ravindran AV, Kennedy SH, Lam RW, et al. Canadian Network for Mood and Anxiety Treatments (CANMAT) clinical guidelines for the management of major depressive disorder in adults. II. Psychotherapy alone or in combination with antidepressant medication. Journal of Affective Disorders. 2009;117(Suppl 1):S15-25.

[52] Chiesa A, Serretti A. Mindfulness-based stress reduction for stress management in healthy people: A review and meta-analysis. Journal of alternative and complementary medicine (New York, NY). 2009;15(5):593-600.

[53] Carmody J, Baer RA. How long does a mindfulness-based stress reduction program need to be? A review of class contact hours and effect sizes for psychological distress. Journal of Clinical Psychology. 2009;65(6):627-38.

[54] Ospina MB, Bond K, Karkhaneh M, Buscemi N, Dryden DM, Barnes V, et al. Clinical trials of meditation practices in health care: Characteristics and quality. Journal of Alternative and Complementary Medicine (New York, NY). 2008;14(10):1199-213.

[55] Ledesma D, Kumano H. Mindfulness-based stress reduction and cancer: A meta-analysis. Psycho-Oncology. 2009;18(6):571-9.

[56] Coelho HF, Canter PH, Ernst E. Mindfulness-based cognitive therapy: Evaluating current evidence and informing future research. Journal of Consulting and Clinical Psychology. 2007;75(6):1000-5.

[57] Winbush NY, Gross CR, Kreitzer MJ. The effects of mindfulness-based stress reduction on sleep disturbance: A systematic review. Explore (New York, NY). 2007;3(6):585-91.

[58] Matchim Y, Armer JM. Measuring the psychological impact of mindfulness meditation on health among patients with cancer: A literature review. Oncology Nursing Forum. 2007;34(5):1059-66.

[59] Tremblay A, Sheeran L, Aranda SK. Psychoeducational interventions to alleviate hot flashes: A systematic review. Menopause (New York, NY). 2008;15(1):193-202.

[60] Ott MJ, Norris RL, Bauer-Wu SM. Mindfulness meditation for oncology patients: A discussion and critical review. Integrative Cancer Therapies. 2006;5(2): 98-108.

[61] Krisanaprakornkit T, Krisanaprakornkit W, Piyavhatkul N, Laopaiboon M. Meditation therapy for anxiety disorders. The Cochrane Database of Systematic Reviews. 2006(1):CD004998.

[62] Smith JE, Richardson J, Hoffman C, Pilkington K. Mindfulness-Based Stress Reduction as supportive therapy in cancer care: Systematic review. Journal of Advanced Nursing. 2005;52(3):315-27.

[63] Grossman P, Niemann L, Schmidt S, Walach $H$. Mindfulness-based stress reduction and health benefits. A meta-analysis. Journal of Psychosomatic Research. 2004;57(1):35-43.

[64] Shapiro SL, E. SD, E. SG. Stress management in medical education: A review of the literature. Academic Medicine. 2000;75(7).
[65] Baer RA. Mindfulness training as a clinical intervention: A conceptual and empirical review. Clinical Psychology: Science and Practice. 2003;10(2).

[66] Fann Jr HTSKG. Treatment for depression after traumatic brain injury: A systematic review. Journal of NeuroTrauma. 2009;26(12).

[67] Merkes M. Mindfulness-based stress reduction for people with chronic diseases. Australian Journal of Primary Health. 2010;16(3).

[68] Bernardy K FNKVHW. Efficacy of cognitive-behavioral therapies in fibromyalgia syndrome: A systematic review and metaanalysis of randomized controlled trials. Journal of Rheumatology. 2010;37(10).

[69] Glombiewski Ja SATGJKKRWHSG. Psychological treatments for fibromyalgia: A meta-analysis. Pain. 2010;151(2).

[70] Feng Cy CHCCHCYSCTHCYHCYCCKR. The effect of cognitive behavioral group therapy for depression: A meta-analysis 2000-2010. Worldviews on EvidenceBased Nursing. 2012;9(1).

[71] Mars TS, Abbey H. Mindfulness meditation practise as a healthcare intervention: A systematic review. International Journal of Osteopathic Medicine. 2010;13(2):56-66.

[72] Proulx K. Integrating mindfulness-based stress reduction. Holistic Nursing Practice. 2003;17(4):201-8.

[73] Katz D, Toner B. A systematic review of gender differences in the effectiveness of mindfulness-based treatments for substance use disorders. Mindfulness. 2013;4(4):31831.

[74] McCarney R, Schulz J, Grey A. Effectiveness of mindfulness-based therapies in reducing symptoms of depression: A meta-analysis. European Journal of Psychotherapy and Counselling S2- European Journal of Psychotherapy, Counselling and Health. 2012;14(3):27999.

[75] Eberth J, Sedlmeier P. The effects of mindfulness meditation: A meta-analysis. Mindfulness. 2012;3(3):174-89.

[76] Escuriex BF, Labbé EE. Health care providers' mindfulness and treatment outcomes: A critical review of the research literature. Mindfulness. 2011;2(4):242-53.

[77] Teleki JW. Mindfulness-based stress reduction: A meta-analysis of psychological outcomes. Dissertation Abstracts International: Section B: The Sciences and Engineering S2- Dissertation Abstracts International. 2010;71(3-B):2063.

[78] Boteva K. Mindfulness meditation in patients with mood disorders Feasibility, safety and efficacy: An empirical review. International Journal of Child Health and Human Development. 2008;1(2):135-54.

[79] de Vibe M, Bjørndal A, Tipton E, Hammerstrøm K, Kowalski K. Mindfulness based stress reduction (MBSR) for improving health, quality of life, and social functioning in adults. Campbell Systematic Reviews. 2012;3.

[80] Toneatto T, Nguyen L. Does mindfulness meditation improve anxiety and mood symptoms? A review of the controlled research. Canadian Journal of Psychiatry Revue Canadienne de Psychiatrie. 2007;52(4):260-6.

[81] Veehof MM, Trompetter HR, Bohlmeijer ET, Schreurs $\mathrm{KM}$. Acceptance- and mindfulness-based interventions for the treatment of chronic pain: A meta-analytic review. Cogn Behav Ther. 2016;45(1):5-31.

[82] Park SH, Han KS. Blood Pressure Response to Meditation and Yoga: A Systematic Review and Meta-Analysis. Journal of Alternative and Complementary Medicine (New York, NY). 2017. 
[83] Gilmartin H, Goyal A, Hamati MC, Mann J, Saint S, Chopra V. Brief Mindfulness Practices for Healthcare Providers - a Systematic Literature Review. The American Journal of Medicine. 2017.

[84] Cavanagh K, Strauss C, Forder L, Jones F. Can mindfulness and acceptance be learnt by self-help? A systematic review and meta-analysis of mindfulness and acceptance-based self-help interventions. Clinical Psychology Review. 2014;34(2):118-29.

[85] Clarke K, Mayo-Wilson E, Kenny J, Pilling S. Can nonpharmacological interventions prevent relapse in adults who have recovered from depression? A systematic review and meta-analysis of randomised controlled trials. Clinical Psychology Review. 2015;39:58-70.

[86] Lao SA, Kissane D, Meadows G. Cognitive effects of MBSR/MBCT: A systematic review of neuropsychological outcomes. Conscious Cogn. 2016;45:109-23.

[87] Jain FA, Walsh RN, Eisendrath SJ, Christensen S, Rael Cahn B. Critical analysis of the efficacy of meditation therapies for acute and subacute phase treatment of depressive disorders: A systematic review. Psychosomatics. 2015;56(2):140-52.

[88] Bawa FL, Mercer SW, Atherton RJ, Clague F, Keen A, Scott NW, et al. Does mindfulness improve outcomes in patients with chronic pain? Systematic review and metaanalysis. The British Journal of General Practice : The journal of the Royal College of General Practitioners. 2015;65(635):e387-400.

[89] Lever Taylor B, Cavanagh K, Strauss C. The Effectiveness of Mindfulness-Based Interventions in the Perinatal Period: A Systematic Review and Meta-Analysis. PloS One. 2016;11(5):e0155720.

[90] Shi Z, MacBeth A. The effectiveness of mindfulnessbased interventions on maternal perinatal mental health outcomes: A systematic review. Mindfulness. 2017.

[91] Noordali F, Cumming J, Thompson JL. Effectiveness of Mindfulness-based interventions on physiological and psychological complications in adults with diabetes: A systematic review. Journal of Health Psychology. 2015.

[92] Abbott RA, Whear R, Rodgers LR, Bethel A, Thompson Coon J, Kuyken W, et al. Effectiveness of mindfulnessbased stress reduction and mindfulness based cognitive therapy in vascular disease: A systematic review and meta-analysis of randomised controlled trials. Journal of Psychosomatic Research. 2014;76(5):341-51.

[93] Cairncross M, Miller CJ. The Effectiveness of Mindfulness-Based Therapies for ADHD: A MetaAnalytic Review. Journal of Attention Disorders. 2016.

[94] Zhang MF, Wen YS, Liu WY, Peng LF, Wu XD, Liu QW. Effectiveness of Mindfulness-based Therapy for Reducing Anxiety and Depression in Patients With Cancer: A Metaanalysis. Medicine. 2015;94(45):e0897-0.

[95] Spijkerman MP, Pots WT, Bohlmeijer ET. Effectiveness of online mindfulness-based interventions in improving mental health: A review and meta-analysis of randomised controlled trials. Clinical Psychology Review. 2016;45:102-14.

[96] Khoury B, Knauper B, Schlosser M, Carriere K, Chiesa A. Effectiveness of traditional meditation retreats: A systematic review and meta-analysis. Journal of Psychosomatic Research. 2017;92:16-25.

[97] Matvienko-Sikar K, Lee L, Murphy G, Murphy L. The effects of mindfulness interventions on prenatal well-being: A systematic review. Psychol Health. 2016;31(12):1415-34.

[98] Shiyko MP, Hallinan S, Naito T. Effects of mindfulness training on posttraumatic growth: A systematic review and meta-analysis. Mindfulness. 2017.

[99] Ruffault A, Czernichow S, Hagger MS, Ferrand M, Erichot $\mathrm{N}$, Carette $\mathrm{C}$, et al. The effects of mindfulness training on weight-loss and health-related behaviours in adults with overweight and obesity: A systematic review and metaanalysis. Obesity Research \& Clinical Practice. 2016.

[100] O'Driscoll M, Byrne S, Mc Gillicuddy A, Lambert S, Sahm LJ. The effects of mindfulness-based interventions for health and social care undergraduate students - a systematic review of the literature. Psychology, Health \& Medicine. 2017;22(7):851-65.

[101] Li G, Yuan H, Zhang W. The Effects of MindfulnessBased Stress Reduction for Family Caregivers: Systematic Review. Arch Psychiatr Nurs. 2016;30(2):292-9.

[102] Stephenson KR, Kerth J. Effects of Mindfulness-Based Therapies for Female Sexual Dysfunction: A MetaAnalytic Review. Journal of Sex Research. 2017:1-18.

[103] Zhang J, Xu R, Wang B, Wang J. Effects of mindfulnessbased therapy for patients with breast cancer: A systematic review and meta-analysis. Complementary Therapies in Medicine. 2016;26:1-10.

[104] Jayewardene WP, Lohrmann DK, Erbe RG, Torabi MR. Effects of preventive online mindfulness interventions on stress and mindfulness: A meta-analysis of randomized controlled trials. Preventive Medicine Reports. 2017;5:150-9.

[105] Maglione MA, Maher AR, Ewing B, Colaiaco B, Newberry $S$, Kandrack R, et al. Efficacy of mindfulness meditation for smoking cessation: A systematic review and meta-analysis. Addict Behav. 2017;69:27-34.

[106] Kuyken W, Warren FC, Taylor RS, Whalley B, Crane C, Bondolfi G, et al. Efficacy of Mindfulness-Based Cognitive Therapy in Prevention of Depressive Relapse: An Individual Patient Data Meta-analysis From Randomized Trials. JAMA Psychiatry. 2016;73(6):565-74.

[107] Farver-Vestergaard I, Jacobsen D, Zachariae R. Efficacy of psychosocial interventions on psychological and physical health outcomes in chronic obstructive pulmonary disease: A systematic review and meta-analysis. Psychother Psychosom. 2015;84(1):37-50.

[108] Jaffray L, Bridgman H, Stephens M, Skinner T. Evaluating the effects of mindfulness-based interventions for informal palliative caregivers: A systematic literature review. Palliative Medicine. 2016;30(2):117-31.

[109] Lo K, Waterland J, Todd P, Gupta T, Bearman M, Hassed $\mathrm{C}$, et al. Group interventions to promote mental health in health professional education: A systematic review and meta-analysis of randomised controlled trials. Advances in health sciences education : Theory and Practice. 2017.

[110] Burton A, Burgess C, Dean S, Koutsopoulou GZ, Hugh-Jones S. How Effective are Mindfulness-Based Interventions for Reducing Stress Among Healthcare Professionals? A Systematic Review and Meta-Analysis. Stress Health. 2017;33(1):3-13.

[111] Wadephul F, Jones C, Jomeen J. The Impact of Antenatal Psychological Group Interventions on Psychological Well-Being: A Systematic Review of the Qualitative and Quantitative Evidence. Healthcare (Basel, Switzerland). 2016;4(2).

[112] Lomas T, Medina JC, Ivtzan I, Rupprecht S, Eiroa-Orosa FJ. The impact of mindfulness on the wellbeing and 
performance of educators: A systematic review of the empirical literature. Teaching and Teacher Education. 2017;61:132-41.

[113] Koren ME, Purohit S. Interventional studies to support the spiritual self-care of health care practitioners: An integrative review of the literature. Holist Nurs Pract. 2014;28(5):291-300.

[114] Regehr C, Glancy D, Pitts A, LeBlanc VR. Interventions to reduce the consequences of stress in physicians: A review and meta-analysis. The Journal of Nervous and Mental Disease. 2014;202(5):353-9.

[115] Salhofer I, Will A, Monsef I, Skoetz N. Meditation for adults with haematological malignancies. Cochrane Database of Systematic Reviews [Internet]. 2016 [cited Cochrane Systematic Reviews. 2017.; (2). Available from: http://onlinelibrary.wiley.com/doi/10.1002/14651858.CD 011157.pub2/abstract http://onlinelibrary.wiley.com/store /10.1002/14651858.CD011157.pub2/asset/CD011157.pd $\mathrm{f}$ ? $\mathrm{v}=1 \& \mathrm{t}=\mathrm{j} 6 \mathrm{ct} 38 \mathrm{hi} \& \mathrm{~s}=\mathrm{e} 0 \mathrm{f} 92 \mathrm{bb} 6 \mathrm{f} 6 \mathrm{e} 5645106149 \mathrm{~d} 8782 \mathrm{bcd}$ ada704f6413.

[116] Hilton L, Maher AR, Colaiaco B, Apaydin E, Sorbero ME, Booth M, et al. Meditation for posttraumatic stress: Systematic review and meta-analysis. Psychological Trauma : Theory, Research, Practice and Policy. 2017;9(4):453-60.

[117] Chan RR, Larson JL. Meditation Interventions for Chronic Disease Populations: A Systematic Review. Journal of Holistic Nursing: Official Journal of the American Holistic Nurses' Association. 2015;33(4):351-65.

[118] Hurley RVC, Patterson TG, Cooley SJ. Meditation-based interventions for family caregivers of people with dementia: A review of the empirical literature. Aging \& Mental Health. 2014;18(3).

[119] Lenz AS, Hall J, Smith LB. Meta-analysis of group mindfulness-based cognitive therapy for decreasing symptoms of acute depression. Journal for Specialists in Group Work. 2016;41(1):44-70.

[120] Huang HP, He M, Wang HY, Zhou M. A meta-analysis of the benefits of mindfulness-based stress reduction (MBSR) on psychological function among breast cancer (BC) survivors. Breast Cancer (Tokyo, Japan). 2016;23(4):568-76.

[121] Huan-Fang L, Chia-Chi K, Tsair-Wei C, Yu-Rung W. A Meta-Analysis of the Effects of Coping Strategies on Reducing Nurse Burnout. Applied Nursing Research. 2016;31(11p).

[122] Theadom A, Cropley M, Smith HE, Feigin VL, McPherson K. Mind and body therapy for fibromyalgia. The Cochrane Database of Systematic Reviews. 2015(4):Cd001980.

[123] Stefanopoulou E, Grunfeld EA. Mind-body interventions for vasomotor symptoms in healthy menopausal women and breast cancer survivors. A systematic review. Journal of Psychosomatic Obstetrics and Gynaecology. 2016:116.

[124] Younge JO, Gotink RA, Baena CP, Roos-Hesselink JW, Hunink MG. Mind-body practices for patients with cardiac disease: A systematic review and meta-analysis. European Journal of Preventive Cardiology. 2015;22(11):1385-98.

[125] Hall HG, Beattie J, Lau R, East C, Anne Biro M. Mindfulness and perinatal mental health: A systematic review. Women and birth: Journal of the Australian College of Midwives. 2016;29(1):62-71.

[126] Olson KL, Emery CF. Mindfulness and weight loss: A systematic review. Psychosomatic Medicine. 2015;77(1): 59-67.
[127] Dunne J. Mindfulness in Anorexia Nervosa: An Integrated Review of the Literature. Journal of the American Psychiatric Nurses Association. 2017:1078390317711250.

[128] Harrison SL, Lee A, Janaudis-Ferreira T, Goldstein RS, Brooks D. Mindfulness in people with a respiratory diagnosis: A systematic review. Patient Education and Counseling. 2016;99(3):348-55.

[129] Katterman SN, Kleinman BM, Hood MM, Nackers LM, Corsica JA. Mindfulness meditation as an intervention for binge eating, emotional eating, and weight loss: A systematic review. Eating Behaviors. 2014;15(2):197-204.

[130] Hilton L, Hempel S, Ewing BA, Apaydin E, Xenakis L, Newberry S, et al. Mindfulness Meditation for Chronic Pain: Systematic Review and Meta-analysis. Ann Behav Med. 2017;51(2):199-213.

[131] Gong H, Ni CX, Liu YZ, Zhang Y, Su WJ, Lian YJ, et al. Mindfulness meditation for insomnia: A meta-analysis of randomized controlled trials. Journal of Psychosomatic Research. 2016;89:1-6.

[132] McConville J, McAleer R, Hahne A. Mindfulness Training for Health Profession Students-The Effect of Mindfulness Training on Psychological Well-Being, Learning and Clinical Performance of Health Professional Students: A Systematic Review of Randomized and Nonrandomized Controlled Trials. Explore (New York, NY). 2017;13(1):26-45.

[133] Oikonomou MT, Arvanitis M, Sokolove RL. Mindfulness training for smoking cessation: A meta-analysis of randomized-controlled trials. Journal of Health Psychology. 2016.

[134] Li W, Howard MO, Garland EL, McGovern P, Lazar M. Mindfulness treatment for substance misuse: A systematic review and meta-analysis. J Subst Abuse Treat. 2017;75:62-96.

[135] Cachia RL, Anderson A, Moore DW. Mindfulness, stress and well-being in parents of children with Autism Spectrum Disorder: A systematic review. Journal of Child and Family Studies. 2016;25(1):1-14.

[136] Kor PPK, Chien WT, Liu JYW, Lai CKY. Mindfulnessbased intervention for stress reduction of family caregivers of people with dementia: A systematic review and metaanalysis. Mindfulness. 2017.

[137] Dhillon A, Sparkes E, Duarte RV. Mindfulness-based interventions during pregnancy: A systematic review and meta-analysis. Mindfulness. 2017.

[138] Rogers JM, Ferrari M, Mosely K, Lang CP, Brennan L. Mindfulness-based interventions for adults who are overweight or obese: A meta-analysis of physical and psychological health outcomes. Obesity Reviews : An Official Journal of the International Association for the Study of Obesity. 2017;18(1):51-67.

[139] Godfrey KM, Gallo LC, Afari N. Mindfulness-based interventions for binge eating: A systematic review and meta-analysis. J Behav Med. 2015;38(2):348-62.

[140] O'Reilly GA, Cook L, Spruijt-Metz D, Black DS. Mindfulness-based interventions for obesity-related eating behaviours: A literature review (Provisional abstract). Database of Abstracts of Reviews of Effects [Internet]. 2014 [cited Cochrane Other Reviews. 2017.; (2):[453-61 pp.]. Available from: http://onlinelibrary.wiley.com/o/co chrane/cldare/articles/DARE-12015001505/frame.html.

[141] Strauss C, Cavanagh K, Oliver A, Pettman D. Mindfulness-based interventions for people diagnosed with a current episode of an anxiety or depressivedisorder: 
A meta-analysis of randomised controlled trials. PloS One. 2014;9(4):e96110.

[142] de Souza IC, de Barros VV, Gomide HP, Miranda TC, Menezes Vde P, Kozasa EH, et al. Mindfulness-based interventions for the treatment of smoking: A systematic literature review. Journal of Alternative and Complementary Medicine (New York, NY). 2015;21(3):129-40.

[143] Haller H, Winkler MM, Klose P, Dobos G, Kummel S, Cramer H. Mindfulness-based interventions for women with breast cancer: An updated systematic review and meta-analysis. Acta Oncol. 2017:1-12.

[144] Wood K, Lawrence M, Jani B, Simpson R, Mercer SW. Mindfulness-based interventions in epilepsy: A systematic review. BMC neurology. 2017;17(1):52.

[145] Virgili M. Mindfulness-based interventions reduce psychological distress in working adults: A meta-analysis of intervention studies. Mindfulness. 2015;6(2):326-37.

[146] Trowbridge K, Mische Lawson L. Mindfulness-based interventions with social workers and the potential for enhanced patient-centered care: A systematic review of the literature. Social Work in Health Care. 2016;55(2):101-24.

[147] Rush SE, Sharma M. Mindfulness-Based Stress Reduction as a Stress Management Intervention for Cancer Care: A Systematic Review. Journal of Evidence-based complementary \& Alternative Medicine. 2016.

[148] Sharma M, Rush SE. Mindfulness-based stress reduction as a stress management intervention for healthy individuals: A systematic review. Journal of Evidence-Based Complementary \& Alternative Medicine. 2014;19(4):27186.

[149] Garmon B, Philbrick J, Becker D, Schorling J, Padrick M, Goodman M, et al. Mindfulness-based stress reduction for chronic pain: A systematic review. Journal of Pain Management. 2014;7(1):23-36.

[150] Khoury B, Sharma M, Rush SE, Fournier C. Mindfulnessbased stress reduction for healthy individuals: A meta-analysis. Journal of Psychosomatic Research. 2015;78(6):519-28.

[151] Crowe M, Jordan J, Burrell B, Jones V, Gillon D, Harris S. Mindfulness-based stress reduction for long-term physical conditions: A systematic review. The Australian and New Zealand Journal of Psychiatry. 2016;50(1):21-32.

[152] Anheyer D, Haller H, Barth J, Lauche R, Dobos G, Cramer H. Mindfulness-Based Stress Reduction for Treating Low Back Pain: A Systematic Review and Meta-analysis. Annals of Internal Medicine. 2017;166(11):799-807.

[153] McLean G, Lawrence M, Simpson R, Mercer SW. Mindfulness-based stress reduction in Parkinson's disease: A systematic review. BMC Neurology. 2017; 17(1):92.

[154] Aucoin M, Lalonde-Parsi MJ, Cooley K. Mindfulnessbased therapies in the treatment of functional gastrointestinal disorders: A meta-analysis. Evidence-based Complementary and Alternative Medicine : eCAM. 2014;2014:140724.

[155] Guillaumie L, Boiral O, Champagne J. A mixed-methods systematic review of the effects of mindfulness on nurses. Journal of Advanced Nursing. 2017;73(5):1017-34.

[156] Chou R, Deyo R, Friedly J, Skelly A, Hashimoto R, Weimer M, et al. Nonpharmacologic Therapies for Low Back Pain: A Systematic Review for an American College of Physicians Clinical Practice Guideline. Annals of Internal Medicine. 2017;166(7):493-505.

[157] Yorke J, Fleming S, Shuldham C, Rao H, Smith HE. Nonpharmacological interventions aimed at modifying health and behavioural outcomes for adults with asthma: A critical review. Clinical and experimental allergy : Journal of the British Society for Allergy and Clinical Immunology. 2015;45(12):1750-64.

[158] van Dessel N, den Boeft M, van der Wouden JC, Kleinstauber M, Leone SS, Terluin B, et al. Nonpharmacological interventions for somatoform disorders and medically unexplained physical symptoms (MUPS) in adults. The Cochrane Database of Systematic Reviews. 2014(11):Cd011142.

[159] Lamothe M, Rondeau E, Malboeuf-Hurtubise C, Duval M, Sultan S. Outcomes of MBSR or MBSR-based interventions in health care providers: A systematic review with a focus on empathy and emotional competencies. Complementary Therapies in Medicine. 2016;24:19-28.

[160] Banks K, Newman E, Saleem J. An Overview of the Research on Mindfulness-Based Interventions for Treating Symptoms of Posttraumatic Stress Disorder: A Systematic Review. Journal of Clinical Psychology. 2015;71(10):935-63.

[161] Whittingham K. Parents of children with disabilities, mindfulness and acceptance: A review and a call for research. Mindfulness. 2014;5(6):704-9.

[162] Gard T, Holzel BK, Lazar SW. The potential effects of meditation on age-related cognitive decline: A systematic review. Annals of the New York Academy of Sciences. 2014;1307:89-103.

[163] Miziou S, Tsitsipa E, Moysidou S, Karavelas V, Dimelis $\mathrm{D}$, Polyzoidou V, et al. Psychosocial treatment and interventions for bipolar disorder: A systematic review. Annals of General Psychiatry. 2015;14:19.

[164] Ivandic I, Freeman A, Birner U, Nowak D, Sabariego C. A systematic review of brief mental health and well-being interventions in organizational settings. Scandinavian journal of Work, Environment \& Health. 2017;43(2): 99-108.

[165] Wylde V, Dennis J, Beswick AD, Bruce J, Eccleston C, Howells N, et al. Systematic review of management of chronic pain after surgery. The British Journal of Surgery. 2017.

[166] Norton AR, Abbott MJ, Norberg MM, Hunt C. A systematic review of mindfulness and acceptance-based treatments for social anxiety disorder. Journal of Clinical Psychology. 2015;71(4):283-301.

[167] Hwang Y-S, Bartlett B, Greben M, Hand K. A systematic review of mindfulness interventions for in-service teachers: A tool to enhance teacher wellbeing and performance. Teaching and Teacher Education. 2017;64:26-42.

[168] Luken M, Sammons A. Systematic Review of Mindfulness Practice for Reducing Job Burnout. The American journal of occupational therapy : Official publication of the American Occupational Therapy Association. 2016;70(2):7002250020p1-p10.

[169] Hulett JM, Armer JM. A Systematic Review of Spiritually Based Interventions and Psychoneuroimmunological Outcomes in Breast Cancer Survivorship. Integrative cancer therapies. 2016;15(4):405-23.

[170] Ravalier JM, Wegrzynek P, Lawton S. Systematic review: Complementary therapies and employee well-being. Occupational medicine (Oxford, England). 2016;66(6):428-36.

[171] Emerson L-M, Leyland A, Hudson K, Rowse G, Hanley P, Hugh-Jones S. Teaching mindfulness to teachers: A systematic review and narrative synthesis. Mindfulness. 2017. 
[172] van Beurden SB, Greaves CJ, Smith JR, Abraham C. Techniques for Modifying Impulsive Processes Associated With Unhealthy Eating: A Systematic Review. Health Psychology. 2016;35(8).

[173] Eilender P, Ketchen B, Maremmani I, Saenger M, Fareed A. Treatment approaches for patients with opioid use disorder and chronic noncancer pain: A literature review. Addictive Disorders \& Their Treatment. 2016;15(2):8598.

[174] Goldstein KM, Shepherd-Banigan M, Coeytaux RR, McDuffie JR, Adam S, Befus D, et al. Use of mindfulness, meditation and relaxation to treat vasomotor symptoms. Climacteric : The journal of the International Menopause Society. 2017;20(2):178-82.

[175] Shrestha N, Ijaz S, Kukkonen-Harjula KT, Kumar S, Nwankwo CP. Workplace interventions for reducing sitting at work. The Cochrane Database of Systematic Reviews. 2015;1:Cd010912.

[176] Dharmawardene M, Givens J, Wachholtz A, Makowski S, Tjia J. A systematic review and meta-analysis of meditative interventions for informal caregivers and health professionals. BMJ Support Palliat Care. 2016;6(2): 160-9.

[177] Cocker F, Joss N. Compassion Fatigue among Healthcare, Emergency and Community Service Workers: A Systematic Review. Int J Environ Res Public Health. 2016;13(6).

[178] Demarzo MMP, Montero-Marin J, Cuijpers P, Zabaletadel-Olmo E, Mahtani KR, Vellinga A, et al. The Efficacy of Mindfulness-Based Interventions in Primary Care: A Meta-Analytic Review. Ann Fam Med. 2015;13(6):57382.

[179] Lee C, Crawford C, Hickey A. Mind-Body Therapies for the Self-Management of Chronic Pain Symptoms. Pain Medicine. 2014;15:S21-S39.

[180] Chen KW, Berger CC, Manheimer E, Forde D, Magidson J, Dachman L, et al. Meditative Therapies for Reducing Anxiety: A Systematic Review and Meta-Analysis of Randomized Controlled Trials. Depress Anxiety. 2012;29(7):545-62.

[181] Fjorback LO, Walach H. Meditation Based Therapies-A Systematic Review and Some Critical Observations. Religions. 2012;3(1):1-18.

[182] Victorson D, Kentor M, Maletich C, Lawton RC, Kaufman VH, Borrero M, et al. Mindfulness Meditation to Promote Wellness and Manage Chronic Disease: A Systematic Review and Meta-Analysis of Mindfulness-Based Randomized Controlled Trials Relevant to Lifestyle Medicine. Am J Lifestyle Med. 2015;9(3):185-211.
[183] Green SM, Key BL, McCabe RE. Cognitive-behavioral, behavioral, and mindfulness-based therapies for menopausal depression: A review. Maturitas. 2015; 80(1):37-47.

[184] Rajguru P, Kolber MJ, Garcia AN, Smith MT, Patel CK, Hanney WJ. Use of Mindfulness Meditation in the Management of Chronic Pain: A Systematic Review of Randomized Controlled Trials. Am J Lifestyle Med. 2015;9(3):176-84.

[185] Cima RFF, Andersson G, Schmidt CJ, Henry JA. Cognitive-behavioral treatments for tinnitus: A review of the literature. J Am Acad Audiol. 2014;25(1):29-61.

[186] Song Y, Lu H, Chen H, Geng G, Wang J. Mindfulness intervention in the management of chronic pain and psychological comorbidity: A meta-analysis. Int J Nurs Sci. 2014;1(2):215-23.

[187] Baranowsky J, Klose P, Musial F, Haeuser W, Dobos G, Langhorst J. Qualitative systemic review of randomized controlled trials on complementary and alternative medicine treatments in fibromyalgia. Rheumatology International. 2009;30(1):1-21.

[188] $\mathrm{Ng}$ Bh THW. Psychophysiological outcomes of health qigong for chronic conditions: A systematic review. Psychophysiology. 2009;46(2).

[189] Goyal M, Singh S, Sibinga EM, Gould NF, RowlandSeymour A, Sharma R, et al. Meditation Programs for Psychological Stress and Well-Being. Comparative Effectiveness Review No. 124. (Prepared by Johns Hopkins University Evidence-based Practice Center under Contract No. 290-2007-10061-I.) AHRQ Publication No. 13(14)-EHC116-EF. Rockville, MD: Agency for Healthcare Research and Quality. 2014.

[190] D'Silva S, Poscablo C, Habousha R, Kogan M, Kligler B. Mind-body medicine therapies for a range of depression severity: A systematic review. Psychosomatics. 2012;53(5):407-23.

[191] Creswell JD. Mindfulness Interventions. Annual Review of Psychology. 2017;68:491-516.

[192] Jamieson SD, Tuckey MR. Mindfulness interventions in the workplace: A critique of the current state of the literature. J Occup Health Psychol. 2017;22(2):180-93.

[193] Mensah SB, Anderson JG. Barriers and facilitators of the use of mind-body therapies by healthcare providers and clinicians to care for themselves. Complement Ther Clin Pract. 2015;21(2):124-30.

[194] Morgan PSJ, Smith A. Health care workers' experiences of mindfulness training: A qualitative review. Mindfulness. 2014. 